\title{
Relato de um caso de fadiga persistente dois anos após pneumonia a Legionella pneumophila
}

Filipa Maria Paixão, ${ }^{1}$ Inês Vinga, ${ }^{2}$ Rita Rogado ${ }^{3}$

\section{RESUMO}

Introdução: A doença dos Legionários (DL) é uma pneumonia causada por bactérias do género Legionella. A transmissão é geralmente inalatória, tendo os adultos com idade > 50 anos, os fumadores, os doentes crónicos e os imunodeprimidos uma suscetibilidade aumentada. A deteção e antibioterapia precoces conduzem geralmente à cura, podendo, todavia, permanecer sequelas.

Descrição do caso: Apresenta-se um caso melhorado, mas não resolvido, de 24 meses de fadiga persistente sem causa identificada, após DL não grave confirmada, numa mulher de 47 anos infetada, depois de ter permanecido duas horas na área do surto de 2014 de Vila Franca de Xira. A doente apresentava, como único fator de risco, tabagismo (ativo e passivo). Foi tratada às $48 \mathrm{~h}$ de evolução com levofloxacina $500 \mathrm{mg} /$ dia durante 13 dias. A melhoria clínica e laboratorial da DL permitiu a alta hospitalar ao quinto dia.

Comentário: Este caso levanta questões relacionadas com fatores de risco e suscetibilidade individual para sintomas residuais, chamando a atenção para a possibilidade de ocorrência de fadiga persistente mesmo após formas não graves de DL e podendo contribuir para a eventual melhoria do acompanhamento médico dos doentes após resolução da DL.

Pelas características da disciplina de medicina geral e familiar (MGF), o médico de família tem um papel crucial no diagnóstico e no acompanhamento de doentes com sintomas residuais de DL, assim como na promoção de hábitos e estilos de vida saudáveis que podem conferir bem estar e mitigar o impacto destes sintomas.

Palavras-chave: Doença dos Legionários; Legionella pneumophila; Fator de risco; Tabagismo; Fadiga crónica.

\section{INTRODUÇÃO}

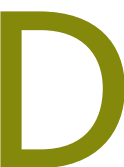

esigna se por doença de Legionários (DL) a doença sistémica manifestada por pneumonia, causada por bactérias do género Legionella. Estas bactérias podem também causar a febre de Pontiac, uma forma de doença localizada nos brônquios, autolimitada, moderada, semelhante a gripe, sem quadro de pneumonia.

A DL é considerada uma doença transmissível de declaração obrigatória desde 1999, sendo monitorizada no contexto do Programa de Vigilância Epidemiológica In-

1. Médica especialista de Medicina Geral e Familiar. UCSP OLIVAIS, ACeS Lisboa Central. 2. Médica Interna de Medicina Geral e Familiar. USF Tejo, ACeS Loures, Odivelas. 3. Assitente Graduada de Medicina Geral e Familiar. USF Tejo, ACeS Loures, Odivelas. tegrada da DL (VigLab - D. Legionários) desde $2004 .{ }^{1}$

A DL apresenta uma variabilidade clínica, dependente da suscetibilidade individual, em termos de gravidade da morbilidade e da mortalidade; assim, a identificação de fatores de risco pré estabelecidos é essencial na definição da abordagem terapêutica, tendo em conta o prognóstico de gravidade estimado. ${ }^{2}$

\section{Transmissão e patogénese da Legionella}

Estão identificadas 52 espécies de Legionella e 70 serotipos, estando cerca de $80 \%$ dos casos associados a $L e$ gionella pneumophila subgrupo 1 (Lpsg1). ${ }^{3}$

A $L p$ é uma bactéria aeróbia gram negativa de multiplicação intracelular facultativa, em macrófagos humanos e em protozoários que funcionam como reservató- 
rios. A estagnação de água, a formação de biofilmes, a presença de algas e protozoários e temperaturas entre 25 ${ }^{\circ} \mathrm{C}$ e $50{ }^{\circ} \mathrm{C}$ favorecem a multiplicação desta bactéria ubiquitária e saprófita da água. ${ }^{4} \mathrm{~A} L p$ sobrevive no exterior, no solo e na água, em baixo número, raramente causando infeções. Contudo, no interior de edifícios, pode multiplicar se em sistemas de água, como torres de refrigeração, sistemas de ar condicionado, fontes decorativas, piscinas, sistemas de água de hotéis ou hospitais até ao nível de contaminação ou dose infetante. ${ }^{5}$

Até fevereiro de 2016 era consensual que a infeção por $L p$ era adquirida sobretudo por via inalatória (e, esporadicamente, por microaspiração de água contaminada); todavia, foi recentemente reportado em Portugal um caso confirmado de provável transmissão interpessoal. ${ }^{6}$

A DL tem um elevado potencial epidémico; surge frequentemente sob a forma de surtos, sobretudo no verão e no outono, podendo ocorrer como casos esporádicos. A OMS define como surto a ocorrência de pelo menos dois casos, num período até seis meses, numa área de residência ou de trabalho comum, em que há suspeita de uma fonte comum de infeção. ${ }^{7}$

O raio de distância de disseminação de aerossóis contaminados é de cerca de $3 \mathrm{~km}$, havendo evidência que possa atingir até $6 \mathrm{~km} .^{8}$

A vigilância das instalações que albergam potenciais fontes de infeção faz parte da prevenção primária, pelo que estas são alvo de inspeções regulares no que respeita à operação e manutenção de sistemas e equipamentos, ao controlo e tratamento físico químico e microbiológico da água, bem como da limpeza e desinfeção de todas as instalações. ${ }^{5}$

A ocorrência de infeção depende ${ }^{4-5}$ não só do grau de contaminação da água, mas também da virulência das bactérias, da contaminação e da disseminação de aerossóis a partir da fonte contaminada, do tempo de exposição aos aerossóis e de fatores de risco do hospedeiro.

\section{Doença dos Legionários}

Os fatores de risco do hospedeiro para a DL são:idade superior ou igual a 50 anos, sexo masculino, hábitos tabágicos ou alcoólicos, imunossupressão e doença crónica (DPOC, diabetes mellitus, doença renal ou oncológica).4-5

O período de incubação varia de dois a dez dias. A apresentação clínica pode ser inespecífica, havendo sintomas classicamente associados a DL, como mal estar, febre alta, prostração, anorexia e cefaleias. As mialgias são menos frequentes, apesar de proeminentes em alguns doentes. Os sintomas das vias respiratórias superiores, como a coriza, são raros. Pelo segundo a terceiro dia, surge tosse ligeiramente produtiva, por vezes hemoptóica, dispneia em cerca de 33-50\% dos doentes e dor torácica. São também frequentes sintomas gastrointestinais (dor abdominal, náuseas, vómitos, diarreia). As alterações neurológicas mais comuns são confusão ou alteração do estado mental, mas também estão descritas letargia, estado confusional, depressão e outros sintomas de encefalopatia. ${ }^{7}$

O pulmão é geralmente a porta de entrada para a $L p$, resultando as manifestações extrapulmonares, sobretudo, da disseminação hematogénica a partir do pulmão.?

O coração é a localização extrapulmonar mais comum (pericardite e endocardite). ${ }^{7}$

Entre o primeiro e o terceiro dia após o início dos sintomas, a confirmação da infeção por $L p s g 1$ pode ser realizada através de um método rápido da pesquisa de antigénios urinários. ${ }^{4,9-10} \mathrm{~A}$ confirmação pode também ser feita por isolamento do agente em cultura de produtos biológicos/biópsia respiratórios (moroso para confirmação de negatividade) e por pesquisa de anticorpos no soro por imunofluorescência indireta. ${ }^{9}$

A avaliação clínica deve também incluir hemograma, ionograma, função hepática e função renal, bem como radiografia ao tórax para avaliar a gravidade e a extensão da doença. ${ }^{9}$

Ao contrário da febre de Pontiac, a DL necessita de tratamento com antibioterapia (macrólido ou quinolona), obrigando frequentemente a hospitalização. ${ }^{7}$

A DL pode condicionar complicações precoces graves, das quais se destacam a insuficiência respiratória, o choque séptico e a insuficiência renal aguda. ${ }^{7}$ Segundo a Organização Mundial da Saúde, a taxa de mortalidade varia entre $5 \%$ a $10 \%$, em função das co morbilidades, do estado imunitário do doente, da gravidade da pneumonia e da precocidade do início da terapia antimicrobiana, podendo atingir $80 \%$ nos doentes imunossuprimidos, nos que não recebem atempadamente tratamento ou naqueles com complicações. ${ }^{?}$

As complicações podem, todavia, perdurar no tempo, como observado num estudo holandês de 144 sobreviventes a um surto da DL adquirida na comunidade (2005), em que foi observada a persistência de fadiga, fraqueza e sintomas neurológicos inespecíficos em $63 \%$ a $75 \%$ dos doentes, até 17 meses após o tratamento ${ }^{10} \mathrm{e}$ até 24 meses, como relatado no surto inicial de Filadélfia em 1976. 
Por outro lado, está descrito que os sintomas residuais podem ser mais arrastados no tempo em doentes com pneumonia adquirida na comunidade que esteja associada a maior risco de vida. ${ }^{10}$

Os critérios de estimativa de prognóstico de gravidade imediata específicos para a pneumonia da comunidade em geral não foram definidos para a DL nem para o prognóstico de suscetibilidade de complicações a longo prazo, que continua a depender de uma avaliação clínica individualizada. ${ }^{11}$

Os cuidados de saúde prestados a nível hospitalar estão tipificados por vários normativos, nomeadamente da Direção-Geral da Saúde, que incluem a confirmação laboratorial do diagnóstico e o seguimento até à resolução da DL e das suas complicações imediatas, não estando previsto um seguimento a longo prazo, após alta, em qualquer orientação clínica. ${ }^{9}$

\section{Fadiga crónica}

As causas de fadiga crónica incluem doenças do foro infecioso (ou status pós infecioso), endocrinológico, hematológico, oncológico, reumatológico, neurológico ou psiquiátrico. A síndroma de fadiga crónica (SFC) é um diagnóstico de exclusão, ${ }^{12}$ corresponde a uma entidade nosológica essencialmente funcional que poderá fazer diagnóstico diferencial de fadiga após exclusão de patologia orgânica.

A SFC é um quadro muito prevalente, que afeta sobretudo pessoas do sexo feminino com idade superior a 40 anos, sendo muito debilitante. Os critérios de diagnóstico do CDC definem a doença como fadiga grave, com mais de seis meses de evolução, associada a quatro dos seguintes sintomas: cefaleia, dor poliarticular (sem edema ou eritema), dor muscular, cansaço de esforço que dura mais de $24 \mathrm{~h}$, alterações da memória de curto prazo e da concentração, odinofagia, adenopatias dolorosas e alterações do sono. ${ }^{12}$

\section{Contexto epidemiológico}

Entre 14 de outubro e 24 de novembro de 2014 ocorreu o segundo maior surto europeu de DL em algumas zonas do município português de Vila Franca de Xira. Este surto foi investigado pelas autoridades de saúde, sendo a provável fonte de emissão de aerossóis contaminados as torres de refrigeração de uma das quatro instalações fabris situadas na região de Alverca.

Foram confirmados, através de antigenúria, 334 casos de infeção por Lpsgl (genótipo mais prevalente ST 1905), dos quais 221 (67\%) eram em indivíduos do sexo masculino, com uma média de idades de 58 anos, tendo sido registados 10 óbitos. ${ }^{13}$

No mês de outubro de 2014 verificou se uma série de condições particularmente profícuas para a multiplicação e disseminação de uma estirpe de Lpsgl muito virulenta, em que se conjugaram elevadas temperaturas do ar, diminuição da espessura da camada limite da atmosfera, presença de uma massa de ar com poeiras proveniente de África e elevada humidade relativa numa zona industrial de alta densidade populacional.

A USF Tejo serve a população de Moscavide, localidade que dista cerca de $14 \mathrm{~km}$ da provável fonte de disseminação da infeção (Figura 1), ou seja, fora da área do surto.

\section{DESCRIÇÃO DO CASO}

C.S., 47 anos de idade, sexo feminino, leucodérmica, natural de Lisboa, casada, pertence a uma família nuclear na fase I do ciclo de Duvall è classe social média de Graffar, com seis anos de escolaridade, caixa fixa em sala de jogos, residente em Moscavide.

C.S. parecia ter uma vida pessoal e familiar preenchida, era ativa e aparentemente realizada.

Era saudável até à data de 10 de novembro de 2014 $(\mathrm{D} 0=$ dia 0$)$, quando recorreu à consulta de doença aguda da USF Tejo por febre alta (temperatura axilar de $39^{\circ} \mathrm{C}$ ), arrepios, mal estar geral, prostração, mialgias, cefaleias, dispneia, tosse seca, náuseas e vómitos, com $48 \mathrm{~h}$ de evolução. Negava queixas de expetoração, dor torácica, odinofagia ou otalgia. Para obter descidas da temperatura axilar até próximo de $37^{\circ} \mathrm{C}$ necessitou de efetuar tomas de paracetamol 1000mg de $6 \mathrm{em} 6 \mathrm{~h}$.

No dia 30 de outubro de 2014, 11 dias antes do início dos sintomas (D-11=dia 11), a doente tinha se deslocado de carro por um período de duas horas, na companhia do marido, à área do surto (Forte da Casa) para limpeza de um apartamento, não tendo permanecido em ambiente exterior. Nas duas semanas anteriores não tinha efetuado quaisquer deslocações à área do surto.

Em termos de antecedentes pessoais havia a registar excesso de peso $\left(58 \mathrm{Kg}\right.$ com IMC $\left.26,1 \mathrm{Kg} / \mathrm{m}^{2}\right)$, hipercolesterolemia e hábitos tabágicos de 15 UMA, sendo a sinvastatina $20 \mathrm{mg}$ e a contraceção hormonal combinada oral as únicas terapêuticas crónicas que efetuava. A doente era, desde há 27 anos, caixa fixa numa sala de jogos onde estava exposta a fumo de tabaco durante o seu horário de trabalho por turnos de $6 \mathrm{~h}$ diárias. Os antece- 
dentes familiares são clinicamente irrelevantes.

Ao exame físico apresentava-se apirética, com sudorese aumentada e extremamente prostrada, com frequência respiratória de $24 \mathrm{cpm}$, frequência cardíaca de 109bpm, pressão arterial de 130/69mmHg, embora com uma saturação periférica de oxigénio em ar ambiente de 99\%. À auscultação pulmonar tinha uma diminuição do murmúrio vesicular à direita, sem ruídos adventícios e som claro pulmonar à percussão. $\mathrm{O}$ restante exame objetivo era normal.

Referenciou-se a doente ao serviço de urgência (SU) do hospital de referência. À entrada no SU, apresentava antigénio urinário Lpsg1 positivo, leucocitose de $13,20 \times 10^{9} / \mathrm{L}$, com neutrofilia $\left(89,09 \%-11,76 \times 10^{9} / \mathrm{L}\right)$, elevação da PCR $(426,2 \mathrm{mg} / \mathrm{dl})$, hiponatrémia ligeira de $134 \mathrm{mEq} / \mathrm{L}$, hipoxémia e alcalose respiratória na gasimetria (pH 7,51; PaCO2 28,6mmHg; PaO2 73,5mmHg; HCO3 22,8mMol/l; lactatos 1,06mg/dl; $\mathrm{SaO}_{2}$ a ar ambiente $95,8 \%$ ), que excluiram insuficiência respiratória. Radiologicamente observava se um foco de condensação no lobo superior direito (Figura 2). Ao terceiro dia de internamento foi avaliada a função hepática, que estava inalterada com valores de AST 17U/L e ALT de 9U/L.

Esteve internada durante cinco dias num serviço de medicina, sob terapêutica com levofloxacina 500mg/dia e.v. Ao longo do internamento registou se uma progressiva melhoria clínica da sintomatologia e da auscultação pulmonar, acompanhada por uma melhoria radiológica e laboratorial que se traduziu por uma descida da PCR para 174,4mg/L, um decréscimo da neutrofilia para valores de $77,8 \%$ (embora mantendo uma leucocitose de $13,6 \times 10^{9} / \mathrm{L}$ ), uma normalização da natrémia para $142 \mathrm{mEq} / \mathrm{L}$ e valores de normoxémia na gasimetria que determinaram a alta medicada com levofloxacina $500 \mathrm{mg} /$ dia oral durante dez dias. O seguimento hospitalar foi efetuado através de uma consulta na semana seguinte à alta, em que se procedeu à confirmação da evolução clínica favorável e à reavaliação radiológica que já não revelava o foco de condensação no lobo superior direito (Figura 3).

Após confirmação do caso, o hospital procedeu à notificação do caso ao Sistema Nacional de Vigilância Epidemiológica (SINAVE).

A doente regressou ao trabalho ao vigésimo segundo dia (D22).

O marido, um homem de 43 anos, hipertenso e não fumador, esteve simultaneamente com a doente na área do surto, não apresentando sintomas de infeção por Legionella. Em julho de 2015, nove meses (M9=mês 9) após o

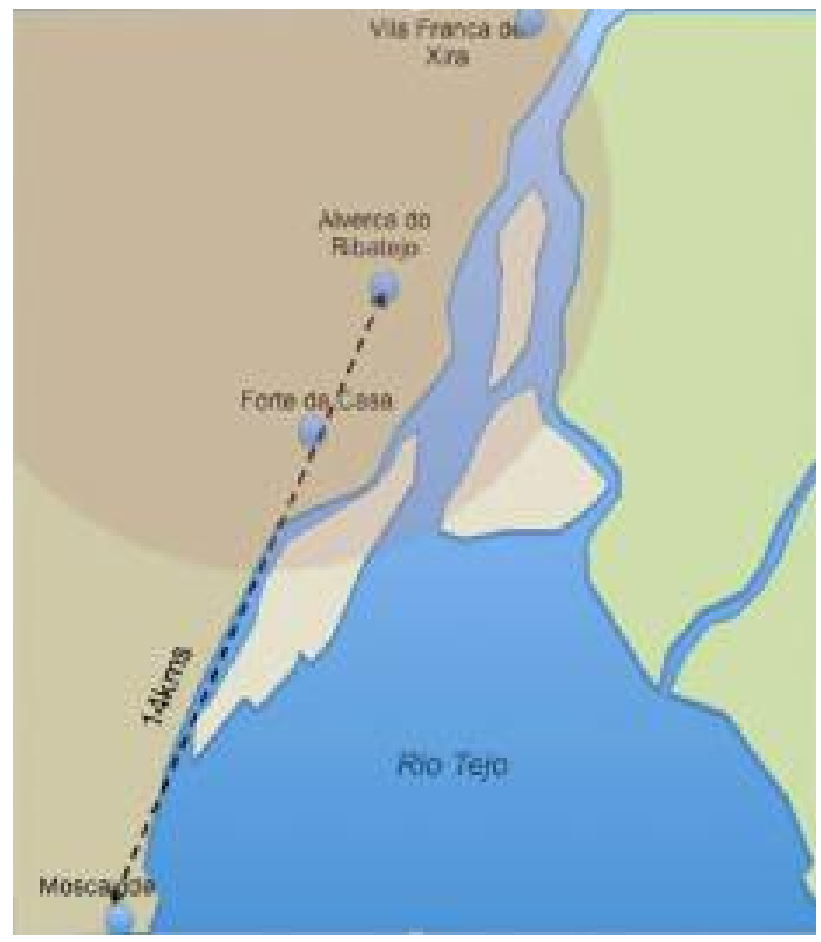

Figura 1. Mapa da região do surto de Legionella de 2014 (Vila Franca de Xira).

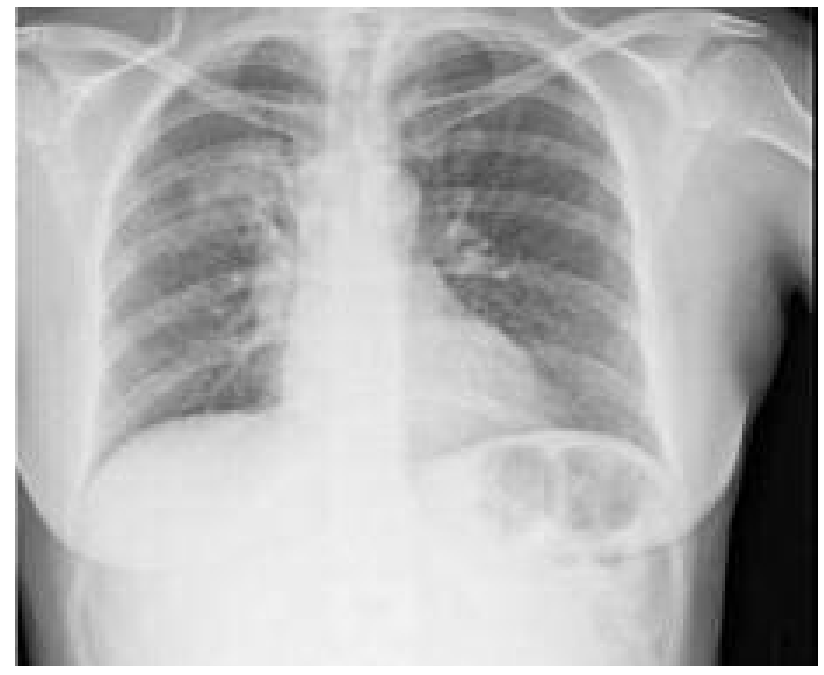

Figura 2. Telerradiografia do tórax (serviço de urgência, 10 de novembro de 2014).

episódio de DL, a doente recorreu de novo à nossa consulta por queixas mantidas de fadiga intensa, que se traduziam em dificuldade nas atividades da vida diária, como pentearse, ter relações sexuais, estender a roupa e subir as escadas da passagem aérea da linha de comboio de Moscavide. 


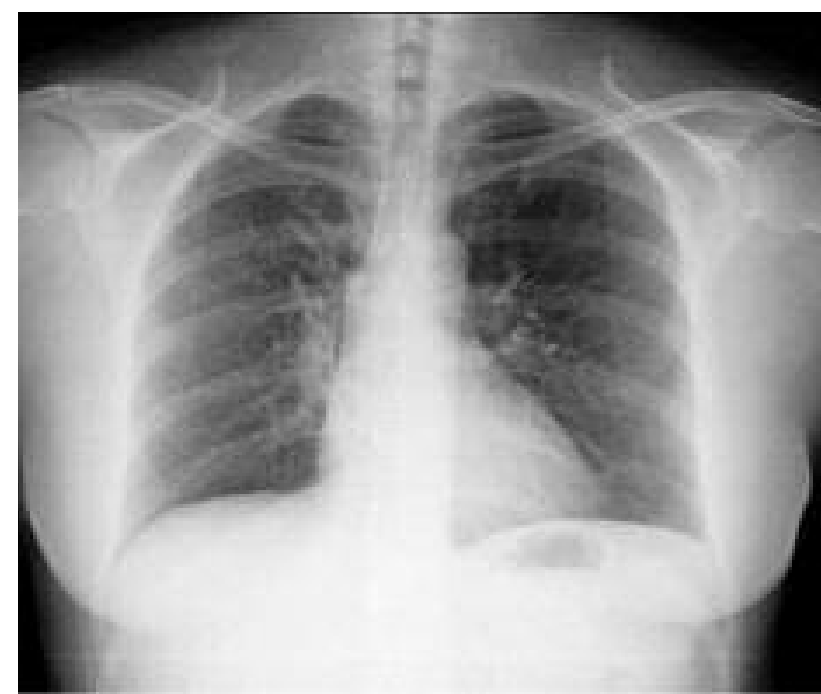

Figura 3. Telerradiografia do tórax (consulta de seguimento, 17 de novembro de 2014).

Negava queixas álgicas, febre, mialgias, artralgias, cefaleias, sintomas digestivos, urinários, psiquiátricos ou neurológicos. Tinha abandonado os hábitos tabágicos por ocasião do internamento, embora mantivesse a exposição passiva ao fumo de tabaco no posto de trabalho. Não apresentava sintomas ou sinais músculo-esqueléticos, neurológicos ou psiquiátricos.

Ao exame objetivo apresentava, à auscultação pulmonar, murmúrio vesicular mantido sem ruídos adventícios e à auscultação cardíaca S1 e S2 rítmicos, normofónicos, taquicárdicos, sem sopros ou extra sons. A pressão arterial era de 155 83mmHg, com frequência cardíaca 93ppm. O peso tinha aumentado $3 \mathrm{Kg}$, para $61 \mathrm{Kg}$ e o IMC subira para $27,5 \mathrm{Kg} / \mathrm{m}^{2}$. Não se identificaram outras alterações no restante exame objetivo.

Em função do quadro clínico foram efetuadas investigações diagnósticas no sentido de excluir as causas mais prováveis de fadiga numa mulher de 47 anos: SFC, anemia, insuficiência cardíaca, insuficiência respiratória, apneia do sono, DPOC, asma, alterações da tiroide, climatério, doenças reumatológicas, infeções ou infestações e doenças psiquiátricas. ${ }^{11}$

Não foram identificadas alterações laboratoriais significativas que validassem qualquer das hipóteses diagnósticas de patologia orgânica consideradas nesta fase, nomeadamente no que respeita: hemograma, VS, PCR, proteinograma, função renal, ionograma, calcémia, função hepática, função tiróideia, marcadores de autoimu- nidade (fator reumatoide, TASO, RA teste, anticorpos antimitocôndrias; dsDNA), pesquisa de ovos e parasitas nas fezes ou urina tipo II.

Quanto à hipótese da insuficiência cardíaca, o ecocardiograma não revelou alterações sugestivas de patologia do foro cardíaco.

Relativamente a psicopatologia, a utente não apresentava sintomas de alterações cognitivas nem as queixas preenchiam os critérios da DSM-5 para depressão major, doença bipolar ou esquizofrenia, conforme a avaliação efetuada na consulta.

Foi excluído o diagnóstico de fibromialgia dada a ausência de sintomas de dor generalizada.

Por último, exclui-se o diagnóstico de SFC por as queixas apresentadas não corresponderem aos critérios dos CDC para SFC (ausência de mialgias, alterações do humor e do sono).

Não tendo sido identificada uma causa para o cansaço ou para a dispneia foi decidido agendar espirometria e manter a utente sob vigilância assídua.

Dados os antecedentes de tabagismo e a idade superior a 35 anos, aproveitou-se a oportunidade para aconselhamento sobre contraceção, pelo que a utente substituiu a contraceção hormonal combinada por contraceção progestagénica oral.

Em setembro de 2015, ao $11^{\circ}$ mês (M11) após o episódio inicial, mantinha praticamente inalteradas as queixas de fadiga e dispneia. Realizou-se na USF a espirometria, que foi efetuada por um técnico cardiopulmonar do serviço de pneumologia do hospital de referência, com um espirómetro portátil (em conformidade com especificações técnicas da norma 005/2016). Dado que o índice de Tiffeneau pré-broncodilatação foi de $75 \%$, o de pós-broncodilatação foi de $78 \%$ e que o aumento do VEMS após broncodilatação foi de $8 \%$ (18ml), não se observaram critérios funcionais de nenhuma das duas doenças obstrutivas consideradas.

Nesta consulta estava normotensa e não se registou aumento de peso.

Em janeiro de 2016, ao $14^{\circ}$ mês (M14), voltou à consulta para reavaliação, apresentando uma ligeira melhoria sintomática, sobretudo das queixas de dispneia, mas continuando a referir sensação de fadiga e cansaço para grandes esforços. Apresentava-se normotensa e com um novo aumento de peso de $2 \mathrm{Kg}$, tendo $63 \mathrm{Kg}$ e um IMC de $28,4 \mathrm{Kg} / \mathrm{m}^{2}$.

Nesta data foram também pedidas provas de função respiratória, em laboratório, com pletismografia, com 
prova de reversibilidade e de provocação inalatória com metacolina. Os resultados revelaram volumes pulmonares, débitos expiratórios forçados e resistência aérea dentro dos limites da normalidade e negatividade da prova de provocação da metacolina (redução do VEMS inferior a 20\%). Foi doseada a alfa 1 antitripsina que estava em valores normais de $200 \mathrm{mg} / \mathrm{dL}$, permitindo excluir uma eventual deficiência desta proteína. Foi simultaneamente pedida TAC torácica de alta definição, que não revelou alterações significativas.

Em fevereiro de 2016, ao $15^{\circ}$ mês (M15) após o início da pneumonia a Legionella, a doente mantinha queixas de fadiga e sensação de dispneia para esforços mais intensos (como caminhar em declive), com uma considerável repercussão geral nas atividades de vida diária, mais acentuadas do que seria expectável após 15 meses de DL, sem identificação de uma alteração causal. O peso corporal não tinha aumentado. Decidimos a referenciação a pneumologia para esclarecimento de eventual associação com DL e para reavaliação clínica de eventuais alterações da função respiratória, apesar de não termos diagnosticado qualquer doença deste foro.

Em março de 2016, $16^{\circ}$ mês (M16), mantinha fadiga menos intensa e negava dispneia. Foi observada na consulta de pneumologia do Hospital Pulido Valente, não se tendo objetivado alterações clínicas. Foram solicitadas novas provas de função respiratória que foram normais e sobreponíveis às anteriores. Estas provas incluíram, pela primeira vez, a prova de difusão de CO para despiste de lesão da membrana alvéolo capilar sugestiva, nomeadamente de patologia do interstício pulmonar (DLCO 104\% e DLCO/VA 85\%). Foi também efetuada prova da marcha de seis minutos, associada com gasimetria, para avaliação da capacidade funcional em deambulação, que revelou boa tolerância ao esforço, sem desencadear cansaço, dor no peito ou dessaturação da hemoglobina (saturação de $\mathrm{O}_{2}$ média $98 \%$ durante a marcha), tendo se registado dispneia moderada de grau 3 da escala de Borg $(0,511$ pontos). Os resultados obtidos contribuíram para a exclusão de alterações restritivas ou obstrutivas significativas. Foi valorizado pelo pneumologista o potencial impacto na fadiga do aumento de $5 \mathrm{Kg}$ no último ano até alcançar um peso de $63 \mathrm{Kg}$ e um IMC de $28,5 \mathrm{Kg} / \mathrm{m}^{2}$, pelo que foi sugerido emagrecimento e prática de exercício. A doente iniciou hidroginástica três vezes por semana, mas não iniciou o plano alimentar recomendado nas consultas posteriores de medicina geral e familiar.
Em dezembro de 2016, $24^{\circ}$ mês (M24), apresenta se francamente melhorada da fadiga, tendo recuperado a capacidade de esforço para quase todas as atividades da vida diária, exceto para andar em declive e voltar a subir as escadas da passagem aérea sem ter de parar. O peso estabilizou em $63 \mathrm{Kg}$, mas não diminuiu. Foi reiterada a importância da manutenção da cessação tabágica, da alimentação saudável e da diminuição do peso adquirido, tendo a utente manifestado a intenção de retomar, no ano novo, o plano alimentar acordado.

Ao ser questionada sobre o impacto destes sintomas, respondeu que "mudou a minha vida familiar e profissional em termos de cansaço. Deixei de fumar e comecei a fazer desporto. Ainda me sinto cansada, mas faço quase a minha vida normal".

Após a realização desta última consulta considerou-se que haviam sido efetuadas as investigações necessárias para excluir causas orgânicas prováveis ou graves de fadiga (Figura 4), tendo sido decidido manter vigilância semestral em consulta.

\section{COMENTÁRIO}

No presente trabalho apresentou-se um caso de 24 meses de fadiga persistente com repercussão nas atividades da vida diária após DL não grave, confirmada, numa utente de 47 anos, infetada durante o surto de 2014 de Vila Franca de Xira e tratada com 13 dias de levofloxacina. A fadiga persistente foi-se atenuando, mas não se resolveu ao longo de 24 meses.

A doente revelou se particularmente suscetível à infeção, dado que residia fora da área do surto, a cerca de $14 \mathrm{~km}$ da fonte emissora de aerossóis, tendo permanecido apenas duas horas no local de risco (na maior parte do tempo, em ambiente interior) e apresentando, como único fator de risco, a exposição ao fumo do tabaco (carga tabágica de 15 UMA em ambiente laboral), dado ter uma idade $<50$ anos, ser do sexo feminino e não ser portadora de doença crónica conhecida.

A discussão deste caso centrou-se nos tópicos abaixo discutidos, que foram relativos à necessidade de referenciação de queixas inespecíficas aos cuidados hospitalares, à relação da infeciosidade com as características do surto, à associação entre fadiga crónica e infeção por $L p$, à importância do tabagismo na fadiga pós infeciosa persistente, aos parâmetros clínicos relevantes para o prognóstico de complicações de DL a longo-prazo e finalmente à modalidade de seguimento a longo prazo. 


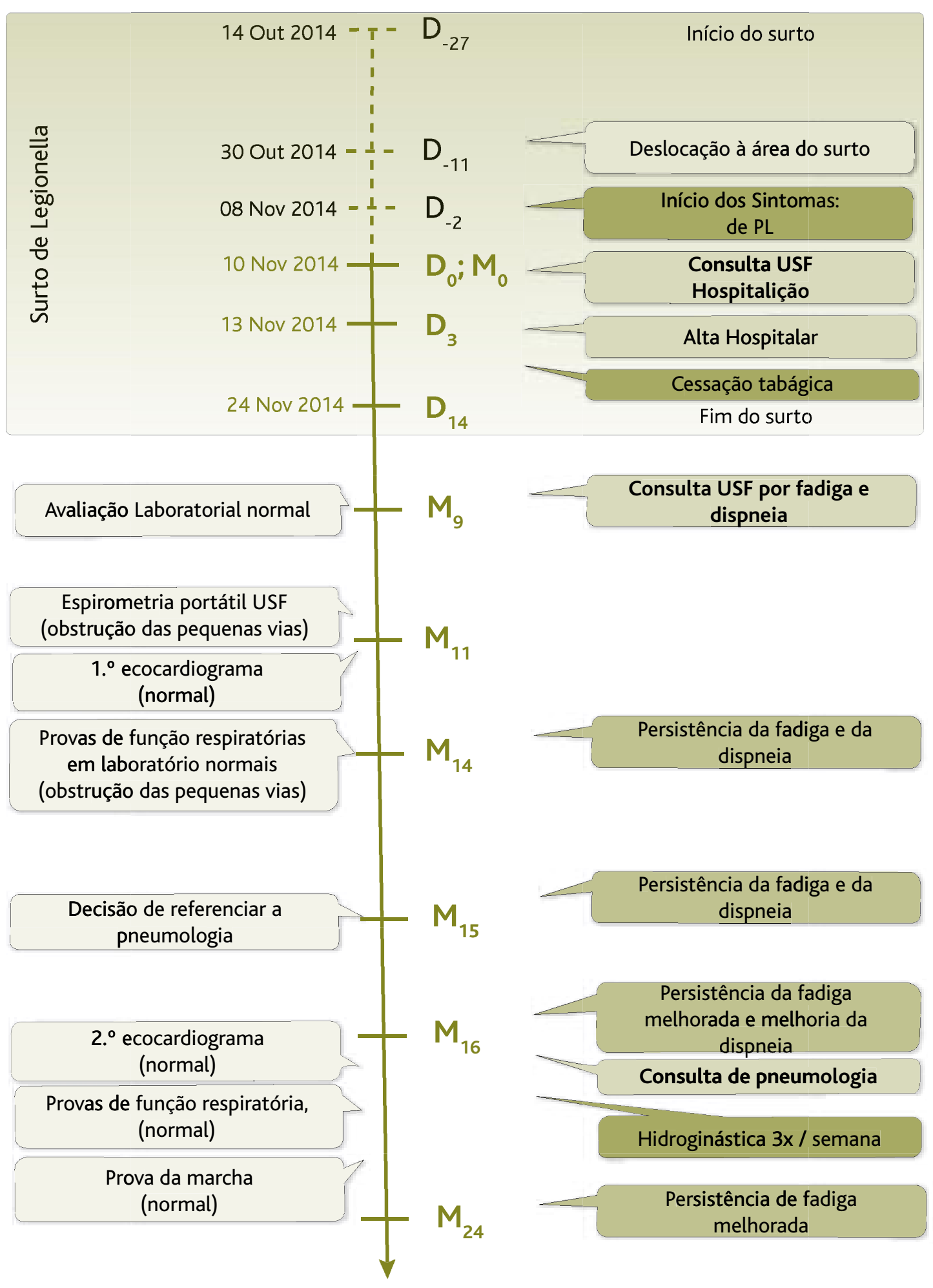

Figura 4. Cronograma da evolução do caso clínico. 
1. Acompanhou-se a doente nos cuidados primários, sem referenciação a qualquer especialidade durante seis meses, devido à inespecificidade dos sintomas. Efetuou-se uma marcha diagnóstica no sentido de excluir as causas mais frequentes de fadiga persistente. Não foi possível relacionar a fadiga persistente com a SFC ou com outra doença. Consequentemente, ao sexto mês decidiu-se referenciá-la à consulta de pneumologia para esclarecimento de eventual associação com DL e para avaliação clínica das alterações da função respiratória ligeiras. Foram excluídas alterações restritivas ou obstrutivas significativas. Foi sugerida diminuição de peso até normalização do IMC e prática de exercício físico regular.

2. Questionou-se sobre a eventual relação entre o aumento de risco de infeção e as características específicas do surto em termos de dose infetante e tempo mínimo de exposição. O facto de a permanência de apenas duas horas no local do surto e em ambiente interior ter sido suficiente para causar doença sugere uma carga bacteriana particularmente elevada. Contudo, o facto de o marido ter permanecido no mesmo local durante o mesmo tempo e não ter sido infetado levantou dúvidas sobre a relevância deste aspecto e privilegiou a abordagem relativa à suscetibilidade aumentada da doente, devido ao tabagismo, como o fator principal e determinante para a contração da doença.

3. A literatura relata a associação de fadiga crónica pós infeciosa em determinadas doenças virais e, mais raramente, bacterianas, havendo evidência científica esporádica para a $L p .{ }^{14}$ Este quadro tem semelhanças com o descrito no artigo do estudo holandês de Lettinga ${ }^{11}$ sobre a persistência de fadiga 17 meses após o tratamento de DL, que menciona que Lattimer já tinha verificado sintomas residuais aos 24 meses nos doentes do surto inicial de Filadélfia, em 1976. Lettinga não identificou nenhum fator predisponente, mas cita Fine, que sugere que os sintomas residuais podem ser mais arrastados no tempo ${ }^{11}$ em doentes com pneumonia adquirida na comunidade que esteja associada a maior risco de vida; todavia, nesta doente a persistência da fadiga até aos 24 meses após a DL não é concordante com a gravidade da pneumonia.

4. Outra questão incidiu sobre se os hábitos tabágicos e a exposição passiva ao fumo do tabaco no local de trabalho (com eventuais repercussões na função respiratória) teriam sido determinantes para a suscetibilidade aumentada à DL, se poderiam predispor à persistência da fadiga. Por este motivo, aconselhou-se e a doente foi apoiada relativamente à manutenção da cessação tabágica (embora não pudesse mudar de emprego).

5. Este quadro de fadiga residual, embora atenuada, ainda persistia aos 24 meses após a pneumonia. Terá havido um impacto favorável da cessação tabágica e da prática de hidroginástica; todavia, persistiu o ambiente laboral e o excesso de peso. Não existem dados clínicos suficientes nem foram encontrados dados na literatura que permitam a elaboração de um prognóstico relativo a intensidade ou duração deste quadro, pelo que se manteve a doente sob vigilância regular, pelo menos de seis em seis meses, para acompanhamento da redução de peso, manutenção do estilo de vida saudável e para monitorização da evolução da fadiga.

\section{CONCLUSÃO}

Este caso levanta questões relacionadas com fatores de risco e suscetibilidade individual para sintomas residuais, chamando a atenção para o problema da possível magnitude destes sintomas e do seu impacto na qualidade de vida, podendo assim contribuir para o reconhecimento precoce de complicações persistentes, mesmo após formas não graves de DL, e para a eventual melhoria do acompanhamento médico dos doentes após resolução da DL.

A disciplina de medicina geral e familiar define-se por um leque de características que incluem, entre outras, a acessibilidade, a abordagem abrangente e holística, a gestão de sintomatologia indiferenciada, a gestão e a integração dos cuidados de saúde contínuos. Por esses motivos e pelas competências da sua especialidade, o médico de família tem um papel crucial no acompanhamento de doentes com sintomas residuais de DL e na promoção de hábitos e estilos de vida saudáveis que podem conferir bem estar e mitigar o seu impacto.

\section{AGRADECIMENTOS}

Os autores agradecem ao Dr. Filipe Froes a observação da utente, o aconselhamento clínico e a revisão deste artigo.

\section{REFERÊNCIAS BIBLIOGRÁFICAS}

1. Portaria n. ${ }^{\circ}$ 1071/98, de 31 de dezembro. Diário da República. $1^{\text {a Sé- }}$ rie-B. 1998;(301). 
2. Fiumefreddo R, Zaborsky R, Haeuptle J, Christ-Crain M, Trampuz A, Steffen I, et al. Clinical predictors for Legionella in patients presenting with community-acquired pneumonia to the emergency department. BMC Pulm Med. 2009;9:4.

3. UK Standards for Microbiology Investigations. Identification of Legionella species [Internet]. London: Public Health England; 2015. Available from: https://assets.publishing.service.gov.uk/government/uploads/system/uploads/attachment_data/file/422702/ID_18i3.pdf

4. Diegues P, Martins V. Prevenção da doenlas dos Legionários: sistemas de tratamento (vantagens e desvantagens). Lisboa: Direção-Geral da Saúde; 2013

5. Soares AS, Pinto A. Prevenção e controlo de Legionella nos sistemas de água [Internet]. Caparica: Instituto Português da Qualidade; EPAL; 2014. ISBN 9789727631490. Available from: http://www1.ipq.pt/PT/SPQ/ComissoesSectoriais/CS04/Documents/Brochura_Legionella_2014.pdf

6. Correia AM, Ferreira JS, Borges V, Nunes A, Gomes B, Capucho R, et al. Probable person-to-person transmission of Legionnaires' disease. $\mathrm{N}$ Engl J Med. 2016;374(5):497-8.

7. World Health Organization. Legionella and the prevention of legionellosis. Geneva:WHO; 2007. ISBN 9241562978

8. Nguyen TM, llef D, Jarraud S, Rouil L, Campese C, Che D, et al. A community-wide outbreak of legionnaires disease linked to industrial cooling towers: how far can contaminated aerosols spread? J Infect Dis. 2006;193(1):102-11.

9. Marques MT, Froes F, Grum G, Esteves AC. Doença dos Legionários: protocolo de diagnóstico. Lisboa: Centro Regional de Saúde Pública de Lisboa e Vale do Tejo; 2003.
10. Direção-Geral da Saúde. Doença dos Legionários [homepage]. Lisboa: DGS; 2018. Available from: https://www.dgs.pt/doenca-dos-legionarios/informacao-para-profissionais/diagnostico.aspx

11. Lettinga KD, Verbon A, Nieuwkerk PT, Jonkers RE, Gersons BP, Prins JM, et al. Health-related quality of life and posttraumatic stress disorder among survivors of an outbreak of Legionnaires disease. Clin Infect Dis. 2002;35(1):11-7.

12. Fine MJ, Auble TE, Yealy DM, Hanusa BH, Weissfeld LA, Singer DE, et al. A prediction rule to identify low risk patients with community-acquired pneumonia. N Engl J Med. 1997;336(4):243-50.

13. Yancey JR, Thomas SM. Chronic fatigue syndrome: diagnosis and treatment. Am Fam Physician. 2012;86(8):741-6.

14. Shivaji T, Sousa Pinto C, San-Bento A, Oliveira Serra LA, Valente J, Machado J, et al. A large community outbreak of Legionnaires' disease in Vila Franca de Xira, Portugal, October to November 2014. Euro Surveill. 2014;19(50):20991.

\section{CONFLITO DE INTERESSES}

Os autores declaram não ter quaisquer conflitos de interesse.

\author{
ENDEREÇO PARA CORRESPONDÊNCIA \\ Filipa Maria Paixão \\ E-mail: filipa.m.paixao@sapo.pt \\ http://orcid.org/0000-0002-0669-7676
}

Recebido em 07-05-2017

Aceite para publicação em 04-10-2018

\section{ABSTRACT}

REPORT OF A CASE OF PERSISTENT FATIGUE AT TWO YEARS AFTER LEGIONELLA PNEUMOPHILA PNEUMONIA Introduction: Legionnaire's disease (LD) is a severe form of pneumonia caused by Legionella spp. Transmission is generally airborne by inhalation of aerosolized particles. Adults older than 50 years of age, smokers, patients with chronic illness and with immunodeficiency, are more prone to infection. Although early detection and antibiotherapy usually lead to a cure, sequelae may remain.

Case description: We present an improved but unresolved case of persistent fatigue during 24 months, in a 47-year-old woman infected after a two-hour stay in the 2014 Vila Franca de Xira outbreak area. The patient had as a sole risk factor: active and passive smoking. A course of 13 days of levofloxacin $500 \mathrm{mg} /$ day was started 48 hours after symptoms begin. Improvement of LD clinical symptoms along with laboratory tests results allowed hospital discharge on the fifth day.

Comment: This case, while raising questions concerning risk factors and individual susceptibility to residual LD symptoms, draws attention to the possibility that persistent fatigue may occur even after non-severe LD and may thus contribute to the eventual improvement of the medical follow-up of patients after the resolution of the LD.

Given the characteristics of the general and family medicine (FGM) discipline, family physicians play a crucial role in monitoring and supporting patients with residual LD symptoms and in promoting healthy habits and lifestyles that can confer well-being and mitigate their impact.

Keywords: Legionnaires' disease; Legionella pneumophila; Risk factor; Tobacco use; Chronic fatigue. 